\title{
Application of Embedded Hardware Device NI myRIO 1900 as a Control Unit for Miniature Mixing Plant
}

\author{
$1^{\text {st }}$ Tugino $^{1}, 2^{\text {nd }}$ Afrizal Ardityawan ${ }^{2}, 3^{\text {rd }}$ Oni Yuliani $^{3}, 4^{\text {th }}$ Asniar $^{4}, 5^{\text {th }}$ Arif Basuki $^{5}$ \\ tugino@itny.ac.id
}

Department of Electrical Engineering, Institut Teknologi Nasional Yogyakarta, Indonesia

\begin{abstract}
Computer-based control processes in the industry have been widely used to replace conventional control processes so that processes in the industry are more optimal. The technology developed in the industry requires practicality in carrying out the control system. This research is focused on the process of mixing ingredients into other materials in two or more phases. The implementation of the control system in the mixing process functions as a regulator of the mixing process that requires special treatment such as setting the stirring speed, the amount of scale of material to be mixed in the tank and the length of the stirring process. In this study also carried out monitoring systems of various conditions such as temperature and height of substances in the mixing tank. The research was conducted using the electronic controller unit of embedded hardware device NI myRIO 1900, and using the function block diagram programming language in LabVIEW software as well as the HMI (Human Machine Interface) design software.The results of a research experiment conducted from a miniature mixing plant system are that the system can work well in accordance with the design. The system can run in accordance with the set point input values that can be entered by the operator through the HMI include, the ratio of material mixture ratio, heater heater set, motor timer set, speed, and rotational direction. Wireless communication that can be reached a maximum of 40 meters.
\end{abstract}

Keyword: electronic Control system, mixing ingredients, Mixing Plant

\section{Introduction}

The application of computer-based control technology to handle processes in industry has been widely used in various types of industries to replace processes that are still conventional in order to make the process in the industry more optimal, technology in the industry demands practicality in running the system. Mixing is an operation that causes random distribution of one material to another where the ingredients are separated in two or more phases, the implementation of the control system in the mixing process serves as a regulator of the mixing process that requires special treatment, such as stirring the speed of the mixer, the amount of material scale which will be mixed in the tank, the duration of the stirring process, as well as monitoring various conditions such as the temperature and hight of the substance in the mixing tank. NI myRIO 1900 is a National Instrument $\AA$ embedded hardware production that also produces LabVIEW 2014 software. The myRIO 1900 board uses dual-core ARM® Cortex TM -A9 and Xilinx FPGA Z-7010 processors to access input and output channels that can be accessed using the MXP connector (myRIO Expansion Port), MSP (myRIO System Port). In the myRIO single board there is an accelerometer sensor embedded on the board as well as WiFi wireless communication support that can be utilized for telemetry purposes for systems that require distance in the process of data acquisition and control of the system to be developed [1]. 
Computer-based control technology in the industrial world is widely used due to more simple of operation and the benefits of the system. With digital monitoring technology, a system in the industry can be easily operated starting from the measurement, processing, and data execution can be done in front of a PC / HMI device with an interface display or interface that is easy to understand so that in its operation humans no longer enter the industrial system kitchen, enough only in front of a computer does not need to go directly to the field [2].

MyRIO National Instruments are used for implementation of controls [6]. MyRIO allows WiFi communication between Segbot and the host computer for surveillance control. LabVIEW is used for real-time data acquisition and control to collect measurement data from accelerometer sensors, level gyros, and wheel position encoders (Matt Migchelbrink et al, 2015). The NI myRIO 1900 Embedded hardware unit can be used as a telemetry unit for temperature and level sensor data acquisition, and can control actuators in the form of motors using PWM and discreate actuators using digital logic as a unit in the miniature mixing plant control system using WiFi wireless communication features that support myRIO [3].

\section{Method}

This research was conducted with the following methods: designing system design concepts, then designing the system consisting of hardware and software design. The system design box diagram is shown in Figure 1. Then the device testing is done to find out the success of the system designed, and the discussion and conclusion is made.

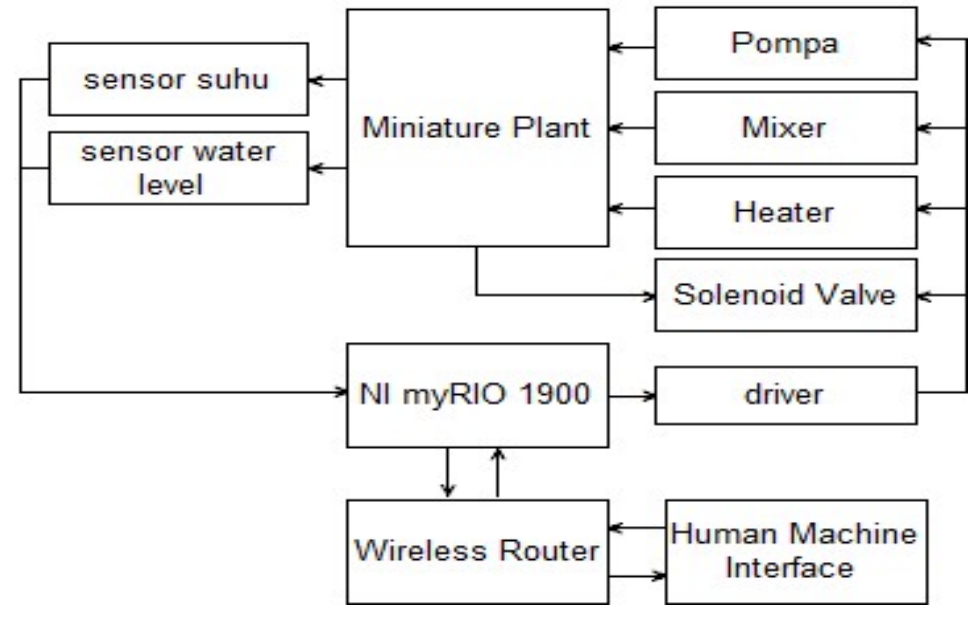

Fig. 1. Block Design System Diagram

The system design starts by making a block diagram of the whole system shown in Figure 1 to find out the input and output that will be used. In the system design will be divided into two stages, namely hardware design, and software design. When designing sensor components, actuators, and NI myRIO 1900, the input output address must be configured so that it can be easier when designing the system and makes it easier to do trouble shooting on the system designed when there are errors or errors that are very likely to occur. NI myRIO 1900 functions as a signal processing unit from sensors in the plant or receiving signal commands from users input via HMI via WiFi wireless communication. 


\section{Results and Discussion}

In the research conducted through 6 times of testing, namely water level sensor testing, temperature sensor testing, actuator driver testing, wireless communication testing, function block program testing, and HMI testing.

3.1 Water Level Sensor

There are 2 types of water level sensors designed. Tank mix can hold as much as $1000 \mathrm{ml}$, batch tanks A - B can accommodate as much as $600 \mathrm{ml}$, and storage tanks can accommodate $200 \mathrm{ml}$. Table 1 shows the measurement results of the tank mix water level sensor here as the first type sensor and in Table 2 the results of the measurement of batch A, B \& Storage water level tank sensors as the second type sensor.

Table 1. Test results for tank mix level sensors

\begin{tabular}{ccccc}
\hline No & $\begin{array}{c}\text { Level } \\
(\%)\end{array}$ & $\begin{array}{c}\text { Multimeter } \\
(\text { Volt })\end{array}$ & $\begin{array}{c}\text { myRIO } \\
(\text { Volt })\end{array}$ & $\begin{array}{c}\text { Error } \\
(\%)\end{array}$ \\
\hline 1 & 10 & 1,33 & 1,33 & 0,00 \\
2 & 20 & 1,41 & 1,40 & 0,71 \\
3 & 30 & 1,55 & 1,56 & 0,64 \\
4 & 40 & 1,66 & 1,66 & 0,00 \\
5 & 50 & 1,71 & 1,73 & 1,15 \\
6 & 60 & 1,82 & 1,81 & 0,54 \\
7 & 70 & 1,92 & 1,91 & 0,52 \\
8 & 80 & 2.01 & 2.01 & 0,00 \\
9 & 90 & 2.13 & 2.13 & 0,00 \\
10 & 100 & 2,21 & 2,21 & 0,00
\end{tabular}

From the test results it can be seen that the tank mix water level sensor using a potentiometer and read using NI myRIO 1900 can be implemented properly with a maximum error rate of $1.15 \%$.

Table 2. Test results for tank level sensors A, B

\begin{tabular}{|c|c|c|c|c|}
\hline No & $\begin{array}{c}\text { Level } \\
(\%)\end{array}$ & $\begin{array}{l}\text { Multimeter } \\
\text { (Volt) }\end{array}$ & $\begin{array}{l}\text { myRIO } \\
\text { (Volt) }\end{array}$ & $\begin{array}{r}\text { Error } \\
(\%)\end{array}$ \\
\hline 1 & 10 & 0,364 & 0,356 & 0,27 \\
\hline 2 & 20 & 0,612 & 0,603 & 1,47 \\
\hline 3 & 30 & 0,925 & 0,922 & 0,32 \\
\hline 4 & 40 & 1,256 & 1,223 & 2,62 \\
\hline 5 & 50 & 1,547 & 1,532 & 0,96 \\
\hline 6 & 60 & 1,831 & 1,843 & 0,65 \\
\hline 7 & 70 & 2,192 & 2,145 & 2,14 \\
\hline 8 & 80 & 2,428 & 2,412 & 0,65 \\
\hline 9 & 90 & 2,739 & 2,721 & 0,65 \\
\hline 10 & 100 & 3,016 & 3,021 & 0,16 \\
\hline
\end{tabular}

From Table 2, the test results it can be seen that the water level sensor tanks A, B \& storage using the principle of voltage dividers and read using NI myRIO 1900 can be implemented well with a maximum error rate of $2.62 \%$. 


\subsection{Temperature Sensor}

Temperature sensors are used to detect changes in temperature in a material mixing vessel in a miniature mixing plant system. The sensor used is the LM 35 sensor. Table 3 shows the results of the design of the LM 35 sensor reading as a temperature sensor. The error obtained is compared with the sensor theory basis on the data sheet issued by the manufacturer with a value of $10 \mathrm{mV} /{ }^{\circ} \mathrm{C}$ compared to a value that can be read by NI myRIO 1900 .

Table 3. Temperature Sensor Testing Results

\begin{tabular}{|c|c|c|c|c|}
\hline \multirow[t]{2}{*}{ No } & Temp & Theory & myRIO & \multirow{2}{*}{$\begin{array}{l}\text { Error } \\
(\%)\end{array}$} \\
\hline & $\left({ }^{\circ} \mathrm{C}\right)$ & $(\mathrm{mV})$ & $(\mathrm{mV})$ & \\
\hline 1 & 25 & 250 & 245 & 2,00 \\
\hline 2 & 30 & 300 & 301 & 0,33 \\
\hline 3 & 35 & 350 & 355 & 1,42 \\
\hline 4 & 40 & 400 & 400 & 0,00 \\
\hline 5 & 45 & 450 & 453 & 0,66 \\
\hline 6 & 50 & 500 & 501 & 0,20 \\
\hline 7 & 55 & 550 & 553 & 0,54 \\
\hline 8 & 60 & 600 & 604 & 0,66 \\
\hline
\end{tabular}

From the data of testing the temperature sensor read by using NI myRIO 1900 seen from the test results table that the reading can be done accurately with a maximum error rate of $2.00 \%$ from the datasheet reference.

\subsection{Actuator Drivers}

Drivers are used to control actuators with the control source can be smaller than the source to be controlled. Figure 3 shows the results of designing sensor drivers and actuators that are designed in one PCB board from several drivers designed

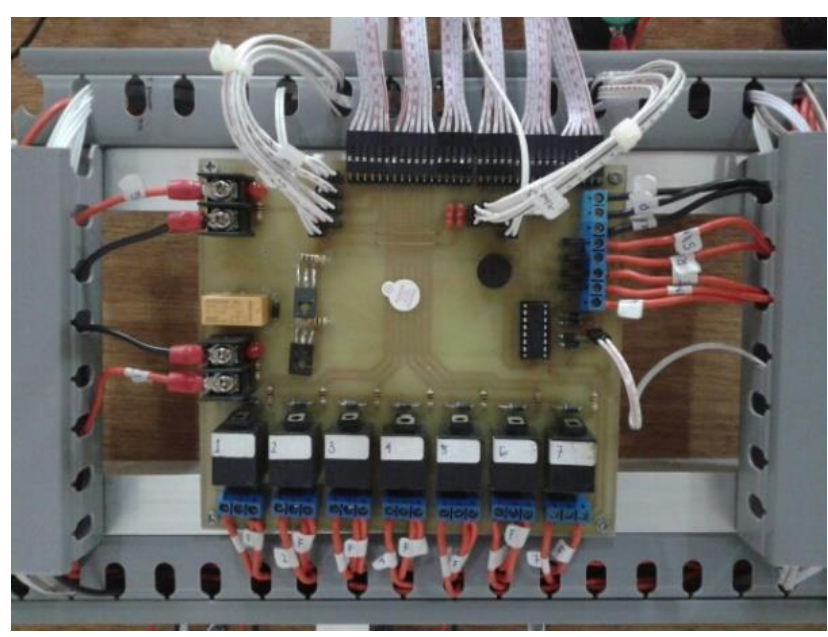

Fig. 3. Driver Design Results 


\subsubsection{Motor Drivers}

The motor driver is used to control the DC motor used to mix in the system used. Table 4 shows the results of testing DC motor drivers that are controlled using PWM.

Table 4. DC Motor Driver Testing Results

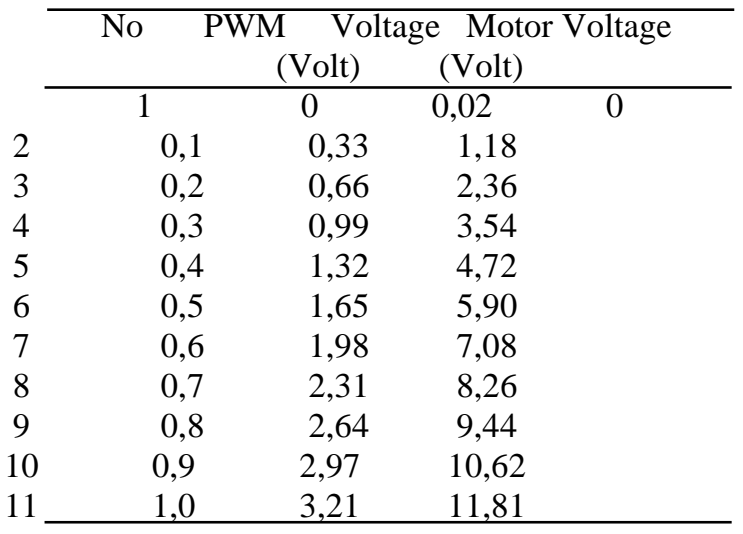

From the investigation data of motor driver, it can be seen in the table that the NPN BD 139 transitor can be used to drive DC motor speed using PWM which is triggered using NI myRIO 1900.

\subsubsection{AC Actuator Drivers}

An actuator is a mechanical device for moving or controlling a mechanism or system or is an element that converts analog electrical quantities into other quantities such as rotation speed and is an electromagnetic device that generates movement power so that it can produce motion. Actuator drivers are designed to be used for actuators that require a working voltage of 220 Volts AC with only 2 conditions which are on or off.

\subsection{Wireless Communication Testing}

Wireless communication is used to send data from data acquisition results sent from NI myRIO to LabVIEW software that is on the PC. Table 5 shows the results of the wireless communication test. From the results of testing the wireless communication that shown on Table 5, can be used at a maximum distance of 0 to 40 meters between the PC as HMI and NI myRIO.

Table 5. The results of the wireless communication

\begin{tabular}{lccc} 
No & PC - myRIO $\begin{array}{c}\text { Time PING } \\
(\text { meter })\end{array}$ & $\begin{array}{c}\text { Information } \\
(\mathrm{ms})\end{array}$ \\
\cline { 2 - 4 } 1 & 5 & 41 & Connected \\
2 & 10 & 42 & Connected \\
3 & 15 & 43 & Connected \\
4 & 20 & 43 & Connected \\
5 & 25 & 54 & Connected \\
6 & 30 & 67 & Connected
\end{tabular}




\begin{tabular}{cccc}
7 & 35 & 66 & Connected \\
8 & 40 & 150 & Connected \\
9 & 45 & Timed Out & Not Connected \\
10 & 50 & Timed Out & Not Connected \\
\hline
\end{tabular}

\subsection{Testing Function Block Diagrams}

Function block diagrams are symbol-based programming designed using LabVIEW software where the program is performed by adding program icons that state syntax and are connected by wires of different colors which mean different data types.

\subsubsection{Trial of digital input}

Digital input programming is used to read the input values given on the AIO myRIO pin. In Figure 4 shown digital input programming and in Table 6. shown the results of digital input programming.

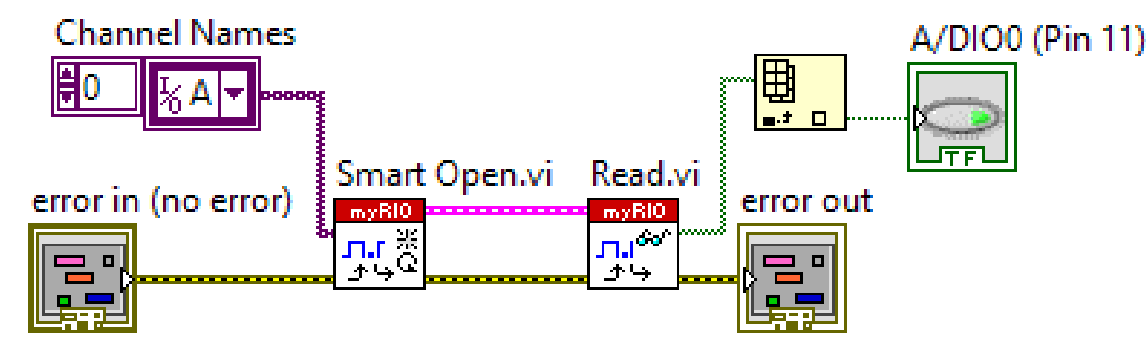

Fig. 4. Function block diagram of a digital input

Table 6. Digital input test results

\begin{tabular}{llcrc} 
No & Logika & $\begin{array}{c}\text { Input } \\
\text { (Volt) }\end{array}$ & $\begin{array}{c}\text { Output } \\
\text { (Volt) }\end{array}$ & $\begin{array}{c}\text { Error } \\
(\%)\end{array}$ \\
1 & HIGH (1) & 4,97 & 4,95 & 0,04 \\
2 & LOW (0) & 0,00 & 0,02 & 0,04 \\
\hline
\end{tabular}

From the testing data the digital input program it can be seen that myRIO can properly read digital logic inputs with the TTL 0 - 5 Volt standard.

\subsubsection{Testing of Analog Input}

Analog input programming is used to read the input values given to AI pins on myRIO. In Figure 5 is presented analog programming input and in Table 7 is indicated the results of analog input programming 0-5 Volts. 


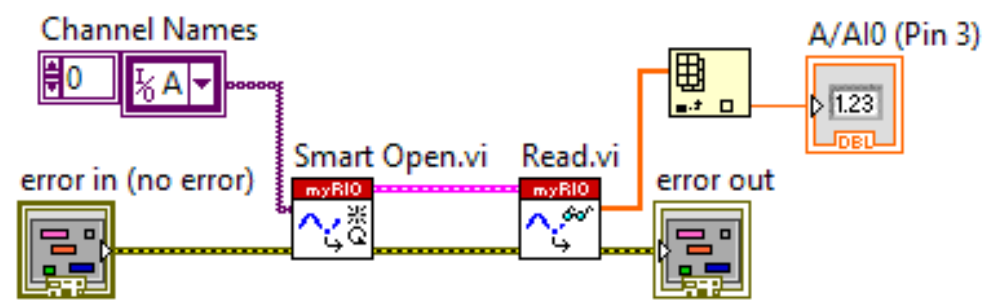

Fig. 5. Analog input diagram function block

Table 7. Test Results for analog input programs

\begin{tabular}{lccc}
\cline { 2 - 4 } No & $\begin{array}{c}\text { Input } \\
\text { (Volt) }\end{array}$ & $\begin{array}{c}\text { output } \\
\text { (Volt) }\end{array}$ & $\begin{array}{c}\text { Error } \\
(\%)\end{array}$ \\
\cline { 2 - 4 } 1 & 0,00 & 0,00 & 0,00 \\
2 & 0,51 & 0,52 & 1,92 \\
3 & 1,12 & 1,12 & 0,00 \\
4 & 1,54 & 1,53 & 0,64 \\
5 & 2,02 & 2,10 & 3,96 \\
6 & 2,53 & 2,59 & 2,37 \\
7 & 3,09 & 3,00 & 2,91 \\
8 & 3,56 & 3,50 & 1,68 \\
9 & 4,01 & 4,02 & 0,24 \\
10 & 4,52 & 4,55 & 0,66 \\
11 & 4,98 & 4,99 & 0,20
\end{tabular}

From the data of the analog input program, it can be seen that NI myRIO can read analog input values accurately with a range of $0-5$ Volts with a maximum error deviation of $3.96 \%$ of the reading results using a digital multimeter.

\subsubsection{Digital Output Test}

Digital output programming is used to control the output on the AIO myRIO pin. In the Figure 6 is shown digital programming output is indicated the results of programming analog output 0-3 Volt.

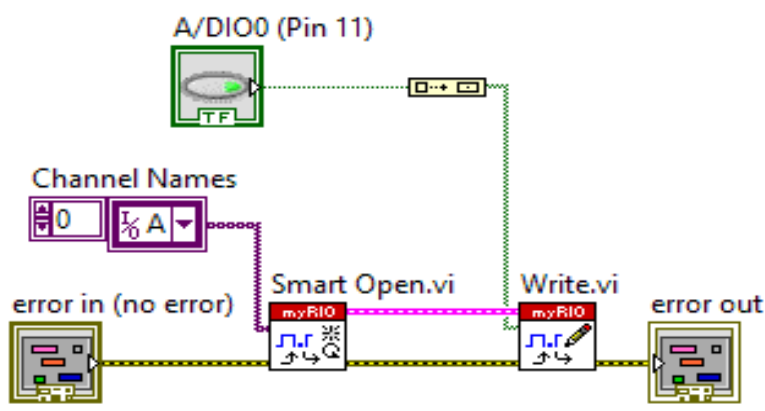

Fig. 6. Digital Output Function Diagram Block 
From the results of testing the digital output program that can be removed from myRIO of 0 - 3.3 Volts can be done well to drive.

\subsubsection{Trial Output of PWM}

Programming the PWM output is used to control the output that is on the AIO myRIO pin. In Figure 7 the digital output programming is shown and in Table 8 the analog output programming results are shown. Figure 8 also shows the PWM configuration in LabVIEW software

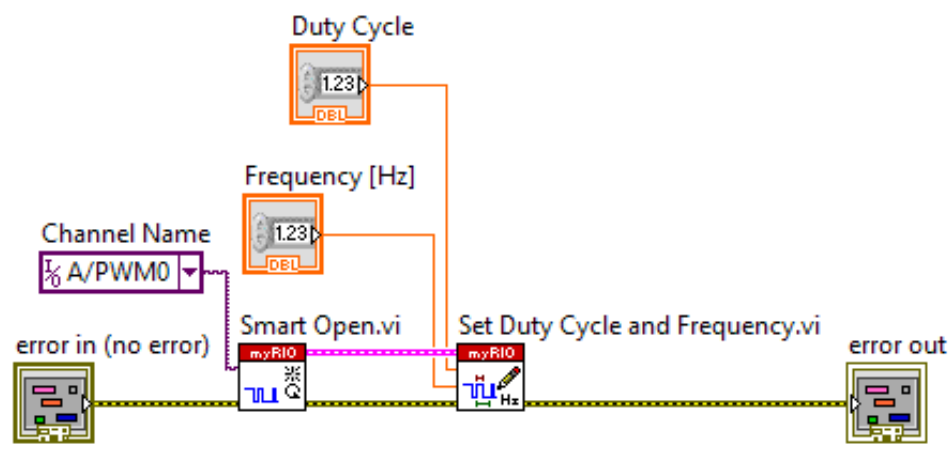

Fig. 7. Function block diagram of PWM output

Table 8. PWM program test results

\begin{tabular}{lcc}
\cline { 2 - 3 } No & PWM & $\begin{array}{c}\text { Output voltage } \\
\text { (Volt) }\end{array}$ \\
\cline { 2 - 3 } 1 & 0,1 & 0,33 \\
2 & 0,2 & 0,66 \\
3 & 0,3 & 0,99 \\
4 & 0,4 & 1,32 \\
5 & 0,5 & 1,65 \\
6 & 0,6 & 1,98 \\
7 & 0,7 & 2,31 \\
8 & 0,8 & 2,64 \\
9 & 0,9 & 2,97 \\
10 & 1 & 3,21 \\
\hline
\end{tabular}

From the test results of PWM output generated using NI myRIO 1900, it can be seen that PWM can be used well with a range of $0-3.3$ Volts and the frequency can be set from 10000 $\mathrm{Hz}$ which can be done before PWM programming.

\subsection{Results of the HMI Design}

HMI was designed using LabVIEW 2014 software and using the function block diagram programming language. After testing the system can run well, set point values can be entered in the mixing process that is running. In figures 8 and 4 the results of the HMI design are shown 

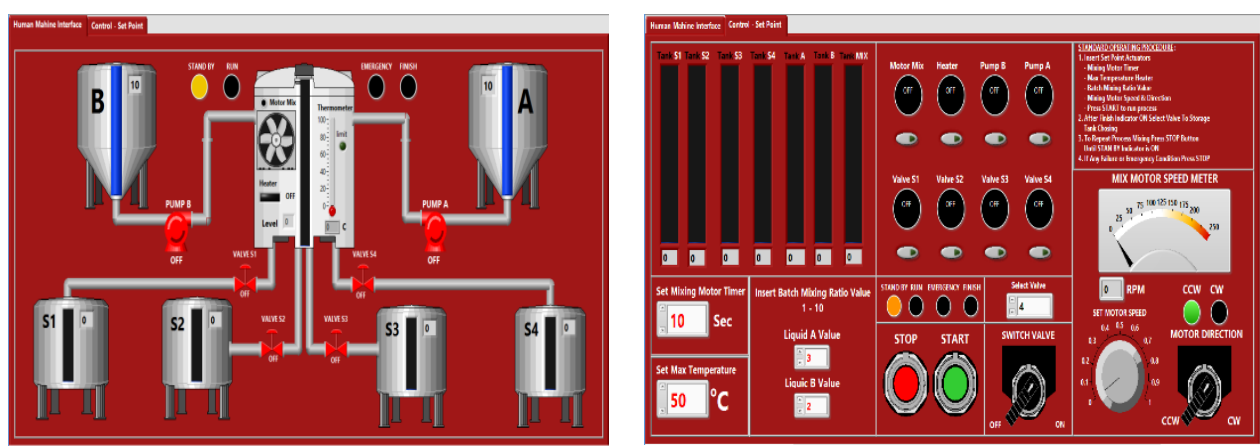

Fig. 8. (a). HMI Front Panel and (b). Front Panel Control-Set Point

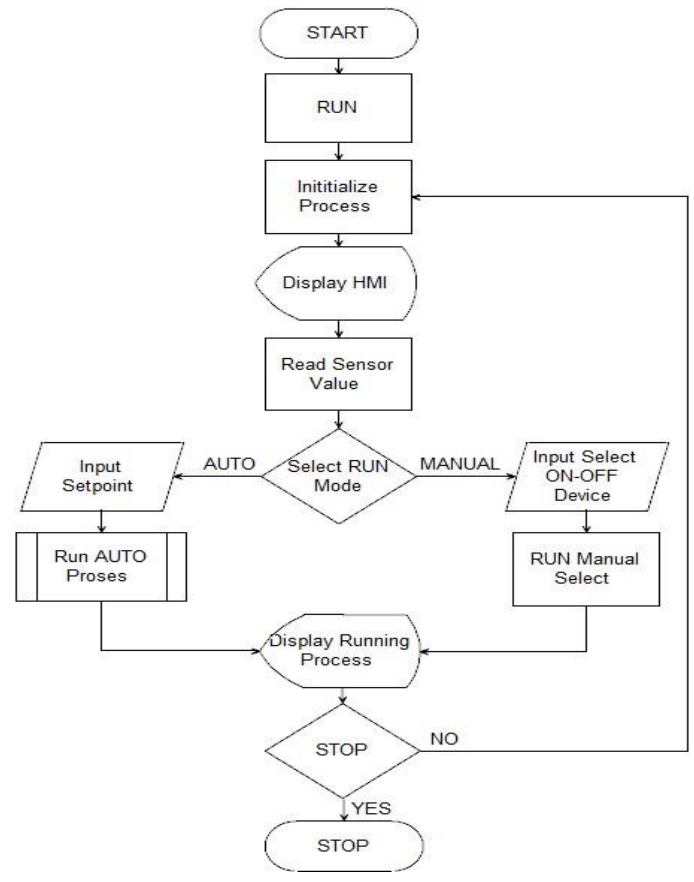

Fig. 9. Running HMI flowchart

After testing the system can run well, set point values can be entered in the mixing process that is running. With the running HMI program flow shown in Figure 9.

\subsection{Results of Miniature Plant Design}

Miniature plant hardware that is designed to have several parts, the front is a miniature plant, and the back is an electronic device and wiring on the system. In Figures 10 the results of system hardware design are shown. 


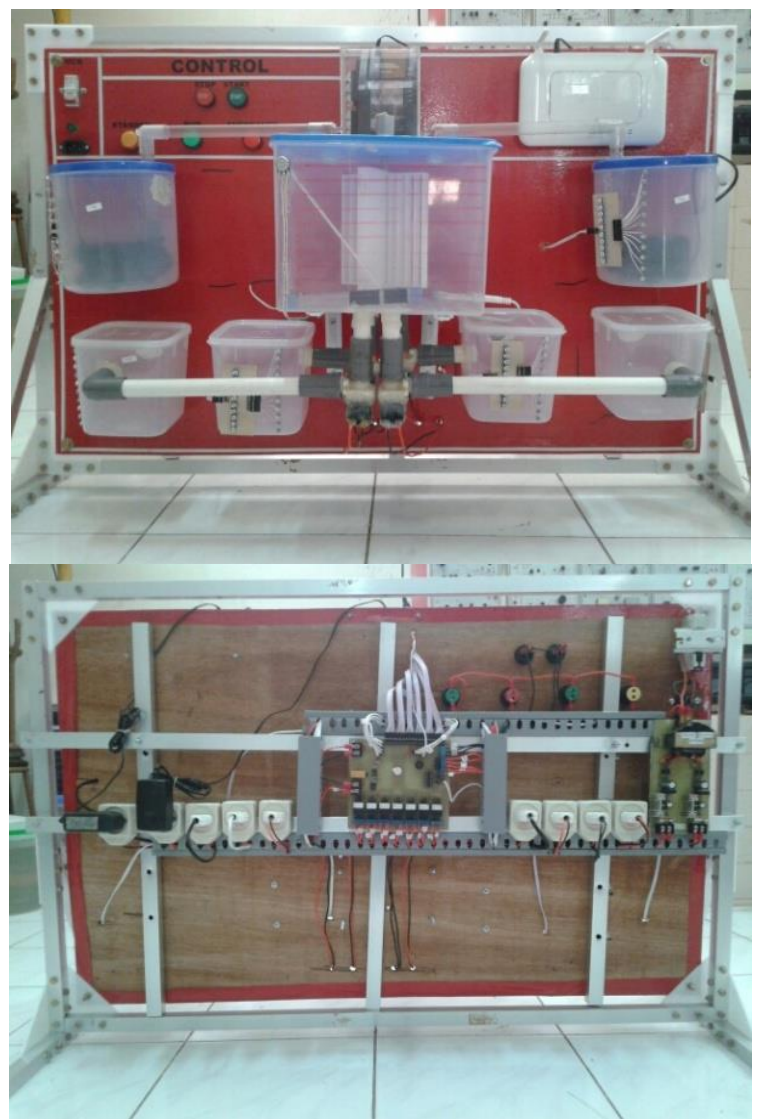

Figure 10. System hardware (a) front side and (b) back side

\section{Conclusions}

The hardware and software in the miniature mixing plant control system have been successfully designed and can run in accordance with the planned functions and performance. The system designed can be used in auto mode and manual mode, with set point values in each process can be input via HMI and can be seen the processes and conditions in the plant. The wireless communication distance that can be reached by NI myRIO 1900 is a maximum of 40 meters.

\section{Acknowledgment}

On this occasion the researcher would like to thank all those who have helped this research from beginning to end. Acknowledgments are also given to the laboratory assistants from the Electrical Engineering Department of ITNY Yogyakarta, who have helped expedite the research conducted. 


\section{References}

[1] Aboud, A. J, R.R, T.A., 2016, Software Defined Radio Implementing GPS Parallel Frequency Space Search Acquisition Algorithm in Real Time Environment, Al-Ahliyya Amman University, Amman, Jordan.

[2] Artanto, D., 2012, Interaksi Arduino dan LabVIEW, Kompas Gramedia, Yogyakarta.

[3] Duy, N.T.K, T.T.H, L.H.D.K., 2015, A Versatile, Low Poweron Monitoring and Control System for Shrimp Farms Based on NI myRIOand Zigbee Network, Department of Automation Technology, Can Tho University, Vietnam.

[4] Migchelbrink, M, W.N.W, L.G., 2015, Design, Build, and Test of an Autonomous myRIO Based Segbot, Mechanical and Nuclear Engineering Department ,Kansas State University, Manhattan, USA.

[5] Palecek, J., M.C., 2016, Emergency Horn Detection Using Embedded Systems, Department of Cybernetics and Biomedical Engineering, Ostrava, Ceko.

[6] Sun, G., 2015, Development of a Wireless Physiological Computing Platform Using a National Instruments' myRIO Embedded Device, Graduate School of Informatics and Engineering, The University of Electro-Communications 1-5-1 Chofugaoka, Chofu, Tokyo 182-8585, Japan. 